\title{
Installing oncofertility programs for common cancers in optimum resource settings (Repro-Can-OPEN Study Part II): a committee opinion
}

\author{
Practice Committee of the Oncofertility Consortium ${ }^{1}$
}

Received: 8 November 2020 / Accepted: 9 November 2020 / Published online: 16 January 2021

(C) Springer Science+Business Media, LLC, part of Springer Nature 2021

\begin{abstract}
Purpose The main objective of Repro-Can-OPEN Study Part 2 is to learn more about oncofertility practices in optimum resource settings to provide a roadmap to establish oncofertility best practice models.

Methods As an extrapolation for oncofertility best practice models in optimum resource settings, we surveyed 25 leading and wellresourced oncofertility centers and institutions from the USA, Europe, Australia, and Japan. The survey included questions on the availability and degree of utilization of fertility preservation options in case of childhood cancer, breast cancer, and blood cancer.

Results All surveyed centers responded to all questions. Responses and their calculated oncofertility scores showed three major characteristics of oncofertility practice in optimum resource settings: (1) strong utilization of sperm freezing, egg freezing, embryo freezing, ovarian tissue freezing, gonadal shielding, and fractionation of chemo- and radiotherapy; (2) promising utilization of GnRH analogs, oophoropexy, testicular tissue freezing, and oocyte in vitro maturation (IVM); and (3) rare utilization of neoadjuvant cytoprotective pharmacotherapy, artificial ovary, in vitro spermatogenesis, and stem cell reproductive technology as they are still in preclinical or early clinical research settings. Proper technical and ethical concerns should be considered when offering advanced and experimental oncofertility options to patients.

Conclusions Our Repro-Can-OPEN Study Part 2 proposed installing specific oncofertility programs for common cancers in optimum resource settings as an extrapolation for best practice models. This will provide efficient oncofertility edification and modeling to oncofertility teams and related healthcare providers around the globe and help them offer the best care possible to their patients.
\end{abstract}

Keywords Oncofertility · Cancer · Optimum resource settings $\cdot$ Best practice $\cdot$ Childhood cancer $\cdot$ Breast cancer $\cdot$ Leukemia . Lymphoma

\section{Introduction}

Several malignancies occur at a young age and may necessitate aggressive anticancer therapies including alkylating chemotherapy and ionizing radiation that could lead to gonadotoxicity and subsequent fertility loss as a devastating side effect. According to the most recent international guide-

Mahmoud Salama

mahmoud.salama@northwestern.edu; eaims_gm@yahoo.com

Teresa K. Woodruff

tkw@northwestern.edu; TeresaWoodruff1989@alum.northwestern.edu

1 The Oncofertility Consortium, Feinberg School of Medicine, Northwestern University, Chicago, IL, USA lines of the American Society of Clinical Oncology (ASCO) and the American Society for Reproductive Medicine (ASRM), several established, debatable, and experimental oncofertility options can be offered to young female and male patients with cancer to preserve and restore fertility [1,2]. Established oncofertility options include sperm freezing, embryo freezing, egg freezing, and recently ovarian tissue freezing and autotransplantation. Debatable oncofertility options include GnRH analogs and hormonal suppression, oophoropexy, gonadal shielding, and fractionation of chemotherapy and radiotherapy. Experimental oncofertility options include oocytes in vitro maturation (IVM), artificial ovary, testicular tissue freezing and autotransplantation, in vitro spermatogenesis, neoadjuvant cytoprotective pharmacotherapy, and stem cell reproductive technology. 
However, such oncofertility international guidelines face several challenges in practice. Over the past years, the Oncofertility Consortium has studied oncofertility practice in many countries within its Oncofertility Professional Engagement Network (OPEN). Our previous studies identified a variety of standards in oncofertility practice around the globe due to limited resource settings, shortage of reproductive care services provided to young patients with cancer, lack of awareness among providers and patients, cultural and religious constraints, lack of insurance coverage, high outof-pocket costs for patients, and lack of funding to support oncofertility programs [3-9]. Despite these challenges, many opportunities exist and create a significant potential for the future including improved cancer survival rates and improved success rates of many oncofertility options as well as emergence of new promising technologies. Therefore as a practical approach, the Oncofertility Consortium recommends installation of specific oncofertility programs for common cancers such as childhood, breast, and blood cancers according to the contemporary challenges and opportunities. This practical approach will provide efficient oncofertility edification and modeling to oncofertility teams and related healthcare providers around the globe and help them offer the best care possible to their patients. To carry out this practical approach, the Oncofertility Consortium has designed its new Repro-Can-OPEN Studies (Reproduction and Cancer in the Oncofertility Professional Engagement Network).

Recently in our Repro-Can-OPEN Study Part 1 published at Journal of Assisted Reproduction and Genetics (JARG) [10], we proposed installation of specific oncofertility programs for common cancers in limited resource settings amidst a current global crisis of the COVID-19 pandemic as well as in 14 developing countries from Africa, Asia, and Latin America. As a further step to reflect the actual wide spectrum of oncofertility practice around the globe and to help provide plausible oncofertility best practice models, we propose here in our Repro-Can-OPEN Study Part 2 installation of specific oncofertility programs for common cancers in optimum resource settings. Our Repro-Can-OPEN Study Part 2 is based on the practical experience of 25 leading and well-resourced oncofertility centers and institutions from the USA, Europe, Australia, and Japan.

\section{Methods}

The Oncofertility Consortium sent the Repro-Can-OPEN Study Part 2 questionnaire via email to 25 leading and wellresourced oncofertility centers and institutions from the USA, Europe, Australia, and Japan (Table 1 and Fig. 1) to be proposed for childhood cancer, breast cancer, and blood cancer. The Repro-Can-OPEN Study Part 2 questionnaire included questions on the availability of fertility preservation options provided to young female and male patients with cancer and whether these options are always, commonly, occasionally, or rarely used. The responses for childhood cancer, breast cancer, and blood cancer from the surveyed centers were collected, reviewed, and analyzed.

To analyze the collected data, our coauthor Dr. Salama from Northwestern University developed the new scoring system "oncofertility score". As previously described [10], the oncofertility score is a new diagnostic tool to measure the availability and utilization of oncofertility options for cancer patients in a treating center, country, or group of centers or countries. It is also a prognostic tool to follow up on the development of oncofertility options and strategies provided to cancer patients over time. The oncofertility score is calculated as a percentile ratio between the actual and maximal points of utilization that an oncofertility option might have (Table 2 and Fig. 2). When a fertility preservation option is available and always used for cancer patients, it is given (Yes ++++$)$ that weighs 100 actual points ( 25 points per each + ). When a fertility preservation option is available and commonly used for cancer patients, it is given (Yes +++) that weighs 75 actual points ( 25 points per each + ). When a fertility preservation option is available but occasionally used for cancer patients, it is given (Yes ++) that weighs 50 actual points $(25$ points per each + ). When a fertility preservation option is available but rarely used or only used in research settings for cancer patients, it is given (Yes + ) that weighs 25 actual points ( 25 points per each + ). When a fertility preservation option is not available, it is given (No) that weighs 0 actual points. When the fertility preservation option is not available to cancer patients because it is still in the preclinical research stage, it is marked with (No*). The maximal point of utilization that an oncofertility option might have is 100 when it is available and always used for cancer patients and is given (Yes ++++) (25 points per each + ).

In this study of 25 surveyed centers, the oncofertility score is calculated as a percentile ratio between the total actual points and the total maximal points of utilization that an oncofertility option might have. The total actual points for an oncofertility option equal the sum of actual points for this option in all 25 surveyed centers. The total maximal points for an oncofertility option equal 100 points multiplied by 25 (number of surveyed centers in this study) resulting in 2500 points.

\section{Results}

All 25 surveyed centers responded to all questions. Each surveyed center has the same serial number in all tables (Tables 1 , 
Table 1 Surveyed oncofertility centers

N Surveyed oncofertility centers

1 Oncofertility Consortium, Feinberg School of Medicine, Northwestern University, Chicago, IL 60611, USA. Ann \& Robert H. Lurie Children's Hospital of Chicago, 225 East Chicago Ave, Box 63, Chicago IL, 60611, USA.

2 Yale Fertility Center and Yale Fertility Preservation program, 200 West Campus Dr., Orange, CT 06477, USA.

3 Karolinska Institutet, Department of Oncology-Pathology and Karolinska University Hospital, Department of Reproductive Medicine, Division of Gynecology and Reproduction, SE-14186, Stockholm, Sweden.

4 Department of Obstetrics and Gynecology, St. Marianna University School of Medicine, 2-16-1, Sugao, Miyamae-ku, Kawasaki, Kanagawa, Japan.

5 Department of Medical Oncology, UOC Clinica di Oncologia Medica, IRCCS Ospedale Policlinico San Martino, Genova, Italy. Department of Internal Medicine and Medical Specialties (DiMI), School of Medicine, University of Genova, Genova, Italy.

6 Fertility Preservation Service, Reproductive Services Unit, Royal Women's Hospital, Parkville, 3051, Australia. Fertility Preservation Service, Melbourne IVF, East Melbourne, 3002, Australia.

7 Children's National Hospital, 111 Michigan Avenue NW, Washington, DC 20010, USA (ZIA\# HD008985).

8 Center for Reproductive Medicine, Michigan Medicine, 475 Market Place, Building 1, Suite B, Ann Arbor, MI 48108, USA.

9 Fertility Research Centre, Royal Hospital for Women, Barker Street, Sydney, Australia.

10 Stanford University Medical Center, 300 Pasteur Drive, Stanford, CA, USA.

11 University of Edinburgh, Edinburgh, UK. Royal Infirmary of Edinburgh and Royal Hospital for Children and Young People, Little France Crescent, Edinburgh, UK.

12 Nationwide Children's Hospital, 700 Children's Dr., Columbus, OH 43205, USA.

13 University of Pennsylvania, Division of Reproductive Endocrinology \& Infertility, 3701 Market Street, Suite 8000, Philadelphia, PA 19104, USA.

14 New York University, NYU Langone Fertility Center, 660 First Ave, 5th Floor, New York, NY 10016, USA.

15 UniKiD - Center for Reproductive Medicine, UniCareD - Center for Fertility Preservation, Düsseldorf University Hospital, Moorenstrasse 5, D-40225 Düsseldorf, Germany.

16 Laboratory of Reproductive Biology, Juliane Marie Centre for Women, Children and Reproduction, University Hospital of Copenhagen, Blegdamsvej 9, DK-2100 Copenhagen, Denmark.

17 Fertility Preservation Service, The Royal Children's Hospital, Flemington Rd, Parkville, Melbourne, Vic 3054, Australia.

18 University of California, San Diego, 3855 Health Sciences Drive, La Jolla, CA 92039-0901, USA.

19 Cliniques Universitaires Saint Luc, Université Catholique de Louvain, Avenue Hippocrate, 10, 1200 Brussels, Belgium. Université Catholique de Louvain, Avenue Mounier 52, 1200 Brussels, Belgium.

20 Fertility Clinic and Research Laboratory on Human Reproduction, CUB-Erasme Hospital, Université Libre de Bruxelles (ULB), 808 route de Lennik, 1070 Brussels, Belgium.

21 Centre for Reproductive Medicine of UZ Brussel, Laarbeeklaan 101, 1090 Brussels, Belgium.

22 Gynecological Endocrinology and Reproductive Medicine Division, Obstetrics and Gynecology Department, Cologne University Hospital, Cologne, Germany.

23 Center for Reproduction and Transplantation, Magee-Womens Hospital, University of Pittsburgh Medical Center, 300 Halket Street, Pittsburgh, PA 15213, USA.

24 University of Cincinnati, Department of Obstetrics and Gynecology, Division for REI, Cincinnati, OH 45229, USA. Cincinnati Children's Hospital Medical Center, Division of Pediatric Adolescent Gynecology Pediatric, Cincinnati, OH 45229, USA.

25 Urology Department, UCSF Medical Center, University of California, San Francisco, CA 94143, USA.

Obstetrics and Gynecology Department, UCSF Medical Center, University of California, San Francisco, CA 94143, USA.

3, 4, and 5). Responses for childhood, breast, and blood cancers and their calculated oncofertility scores are listed in Tables 3, 4, and 5 .

The oncofertility scores for options provided to children with cancer in all 25 surveyed centers were as follows: gonadal shielding in case of irradiation (69\%), ovarian tissue freezing $(63 \%)$, fractionation of chemo- and radiotherapy $(61 \%)$, oophoropexy in case of pelvic irradiation (42\%), testicular tissue freezing $(41 \%)$, GnRH analogs in case of old child (914 years) (35\%), oocyte in vitro maturation (IVM) (18\%), neoadjuvant cytoprotective pharmacotherapy (6\%), artificial ovary $(2 \%)$, in vitro spermatogenesis $(2 \%)$, and stem cells (0\%) (Table 3 and Fig. 3).

The oncofertility scores for options provided to female patients with breast cancer in all 25 surveyed centers were as follows: egg freezing (77\%), IVF/ICSI of frozen oocytes (75\%), gonadal shielding in case of irradiation $(75 \%)$, embryo freezing $(66 \%)$, frozen embryo transfer $(64 \%)$, fractionation of chemo- and radiotherapy (62\%), GnRH analogs (61\%), ovarian tissue freezing (49\%), autotransplantation of frozen 


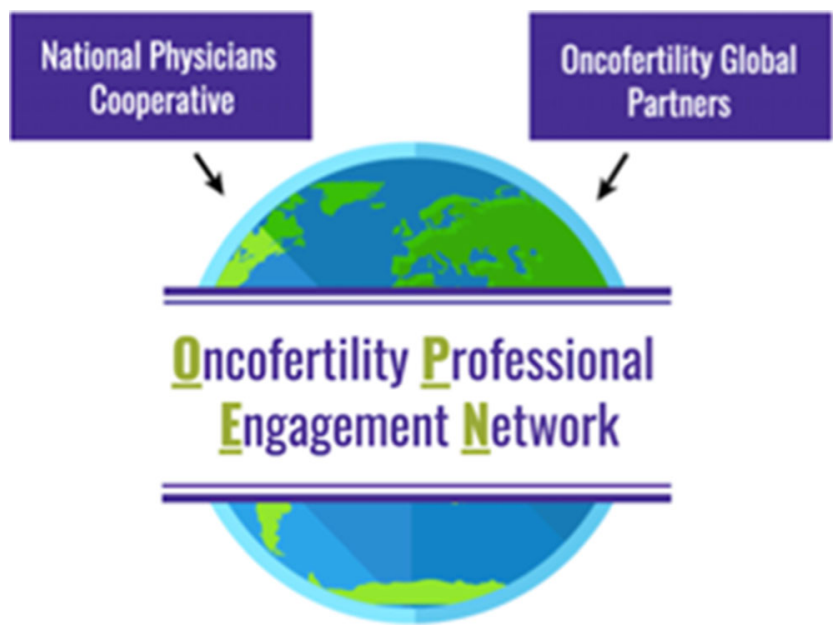

Fig. 1 Merger of American and global networks into one unified network, the Oncofertility Professional Engagement Network (OPEN)

ovarian tissue (43\%), oocyte in vitro maturation (IVM) (23\%), neoadjuvant cytoprotective pharmacotherapy (5\%), artificial ovary (2\%), and stem cells (0\%) (Table 4 and Fig. 4).

The oncofertility scores for options provided to patients with blood cancer in all 25 surveyed centers were as follows: sperm freezing (83\%), gonadal shielding in case of irradiation (75\%), egg freezing (68\%), fractionation of chemo- and radiotherapy $(62 \%)$, embryo freezing (58\%), ovarian tissue freezing (57\%), GnRH analogs (57\%), oophoropexy in case of pelvic irradiation (46\%), testicular tissue freezing (38\%), oocyte in vitro maturation (IVM) $(23 \%)$, neoadjuvant cytoprotective pharmacotherapy (7\%), artificial ovary (2\%), in vitro spermatogenesis $(2 \%)$, and stem cells $(0 \%)$ (Table 5 and Fig. 5).

\section{Discussion}

In our Repro-Can-OPEN Study Part 2, the responses and their calculated oncofertility scores (Tables 3, 4, and 5 and Figs. 3, 4 , and 5) showed three major characteristics of oncofertility practice in optimum resource settings: (1) strong utilization of sperm freezing, egg freezing, embryo freezing, ovarian tissue freezing, gonadal shielding, and fractionation of chemo- and radiotherapy; (2) promising utilization of $\mathrm{GnRH}$ analogs, oophoropexy, testicular tissue freezing, and oocyte in vitro maturation (IVM); and (3) rare utilization of neoadjuvant cytoprotective pharmacotherapy, artificial ovary, in vitro spermatogenesis, and stem cell reproductive technology as they are still in preclinical or early clinical research settings.

Proper technical and ethical concerns should be considered when offering advanced and experimental oncofertility options to patients including gonadal tissue freezing and autotransplantation, in vitro maturation of gametes, artificial gonad technology, neoadjuvant cytoprotective pharmacotherapy, and stem cell reproductive technology. Technically, the aforementioned advanced oncofertility options are sophisticated procedures that require well-resourced oncofertility centers with expert teams of oncologists, reproductive endocrinology and infertility specialists, pediatric and adolescent gynecologists, urologists, pediatric endocrinologists, biologists, embryologists, scientists, and transplantation surgeons. That is why they should be performed only at highly specialized oncofertility centers in optimum resource settings. Early referral of cancer patients to such highly specialized oncofertility centers is strongly recommended. Ethically, most of these advanced oncofertility options are experimental or have limited data on efficacy, and it is essential that they are offered to patients under clear ethical regulations. Special ethical and legal considerations need to be considered in children $[11,12]$. Obtaining ethical approval from the Institutional Review Board (IRB) or the equivalent ethics committee is essential, as is obtaining informed consent from the patients or the legal guardians in the case of a minor. Informed consent for experimental medical treatments and interventions should include the explanation of the procedures, benefits, risks, alternative treatments, and information about the expected outcome and costs. Several oncofertility

Table 2 Oncofertility score calculation

\begin{tabular}{|c|c|c|c|c|c|}
\hline $\begin{array}{l}\text { Availability and utilization of } \\
\text { an oncofertility option }\end{array}$ & $\begin{array}{l}\text { Available and } \\
\text { always used for } \\
\text { cancer patients }\end{array}$ & $\begin{array}{l}\text { Available and commonly } \\
\text { used for cancer patients }\end{array}$ & $\begin{array}{l}\text { Available but } \\
\text { occasionally used } \\
\text { for cancer patients }\end{array}$ & $\begin{array}{l}\text { Available but rarely used or } \\
\text { only used in research settings } \\
\text { for cancer patients }\end{array}$ & Not available \\
\hline Scale symbol & ++++ & +++ & ++ & + & - \\
\hline $\begin{array}{l}\text { Actual points }(\mathrm{AP}) \\
(25 \text { points per }+)\end{array}$ & 100 & 75 & 50 & 25 & 0 \\
\hline $\begin{array}{l}\text { Maximal points (MP) } \\
\text { (100 points per }++++)\end{array}$ & 100 & 100 & 100 & 100 & 100 \\
\hline Oncofertility score $=\mathrm{AP} / \mathrm{MP}(\%)$ & $100 \%$ & $75 \%$ & $50 \%$ & $25 \%$ & $0 \%$ \\
\hline
\end{tabular}


Fig. 2 Oncofertility score calculation

Oncofertility Score $=\frac{\text { Actual Points (AP) of utilization that an oncofertility option might have }}{\text { Maximal Points (MP) of utilization that an oncofertility option might have }} \%$

options are expensive and not fully covered by health insurance in some states and countries, leaving many patients under critical financial pressure. In such complex situations, doctors and patient navigators as well as patient support and advocacy organizations can play an important role in reassuring and guiding patients or legal guardians of minors during counseling [13-18].

\section{Installing oncofertility programs in optimum resource settings}

Based on the responses and their calculated oncofertility scores (Tables 3, 4, and 5 and Figs. 3, 4, and 5), we will try here to tailor and install plausible oncofertility programs for common cancers in optimum resource settings as an extrapolation for best practice models (Table 6). Previous international oncofertility guidelines and recommendations were considered as well [19-35]. Immediately after cancer diagnosis, we recommend early referrals of patients to oncofertility specialists to check the anticancer therapy plan and estimate the related risk of gonadotoxicity and subsequent fertility loss. The risk of anticancer therapyinduced gonadotoxicity and fertility loss depends mainly on the type and stage of the disease, type and dose of anticancer therapy, and the age of the patient at the time of treatment. If the risk of gonadotoxicity and fertility loss is detected or even unknown, a comprehensive multidisciplinary oncofertility strategy should be offered before, during, and after anticancer therapy.

From a practical point of view, an effective oncofertility strategy should be individualized and tailored to the patient's circumstances and it may integrate various established, debatable, and experimental options after proper counseling and obtaining informed consent from the patient or the legal guardians of a minor. It is recommended that the proposed oncofertility strategy should include at least one cryopreservation option. After complete cure from cancer, and when the patient decides to have biological children, a new assessment of reproductive functions should be performed. If anticancer therapy-induced gonadal dysfunction exists, fertility restoration may be achieved by using the cryopreserved gametes or gonadal tissue.

\section{Installing oncofertility programs for childhood cancer in optimum resource settings}

The common forms of childhood cancers that may require aggressive gonadotoxic anticancer therapy and hence necessitate prior fertility preservation measures are leukemia, central nervous system cancers, lymphoma, and sarcomas. Unique medical challenges in oncofertility programs for childhood cancer exist and include the following: (1) freezing of gonadal tissues is the only suitable cryopreservation option before puberty, and (2) autotransplantation of frozen gonadal tissue may carry the risk of reintroducing malignant cells, especially in leukemia which is the most common childhood cancer [36-42].

According to the aforementioned unique medical challenges, as well as the responses and their calculated oncofertility scores (Table 3 and Fig. 3), we suggest installing the following oncofertility programs for childhood cancer in optimum resource settings. Before initiation of anticancer therapy, freezing of prepubertal gonadal tissues (ovarian or testicular tissue) should be encouraged and attempted when possible. In vitro maturation and further vitrification of gametes (oocytes or spermatozoa) and artificial gonad technology (ovary or testis) are still experimental and cannot be relied upon as effective oncofertility options in children. Although experimental, these emerging technologies of in vitro maturation of gametes and artificial gonads aim to provide safe alternatives to avoid future gonadal tissue autotransplantation and potential reintroduction of malignant cells. Oophoropexy before female pelvis irradiation should be attempted when possible. During anticancer therapy, gonadal shielding in case of irradiation should be attempted. Fractionation of chemo- and radiotherapy could be attempted whenever deemed feasible by the oncologists. Use of $\mathrm{GnRH}$ analogs to preserve fertility during chemotherapy in case of older children (9-14 years) is widely debated and needs more research to inform evidence-based practice. Neoadjuvant cytoprotective pharmacotherapy is still experimental and not yet clinically proven as an effective oncofertility option. After anticancer therapy, gonadal function should be monitored to ensure appropriate growth, pubertal development, and reproductive function, with hormone replacement introduced in those with gonadal failure. Furthermore, regular follow-up in survivorship offers a window of opportunity for interval fertility and sexual healthcare, linking patients in with the tissue storage laboratory, and discussing 


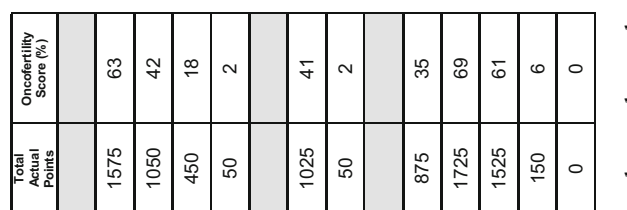

舟

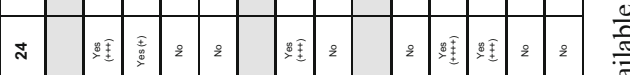

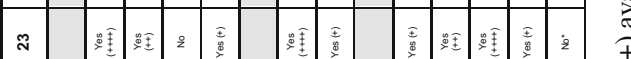

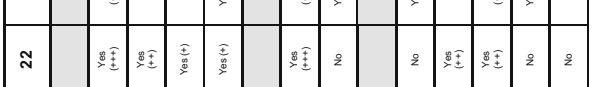

公

\begin{tabular}{|l|l|l|l|l|l|l|l|l|l|l|l|l|l|}
\hline & & & & & & & $>$ & & & & & & \\
\hline & & & & & & & & & & & & & \\
\hline
\end{tabular}

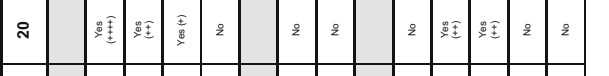

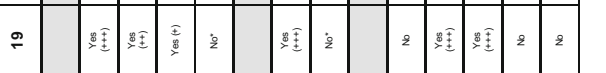

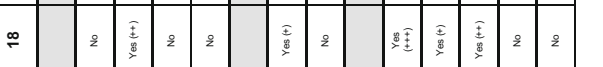

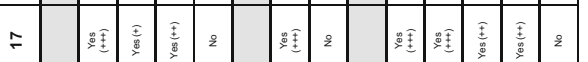

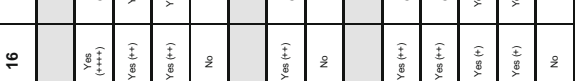

(6)

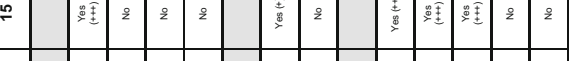

$\pm$

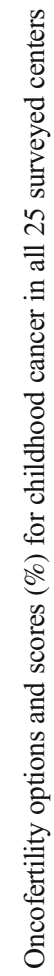

员

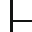

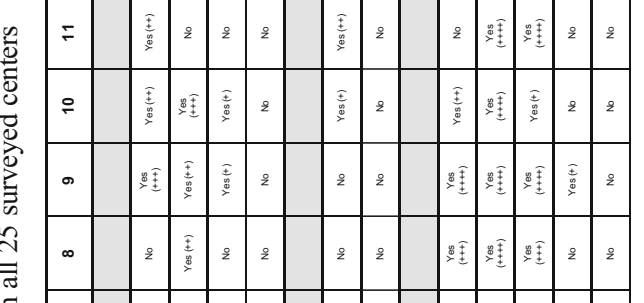

$\simeq$

r

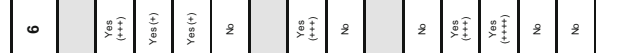

我

के

范

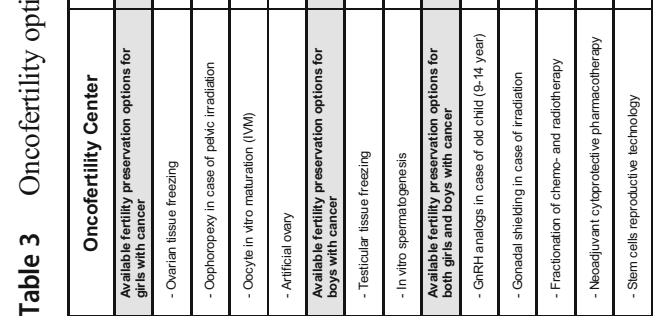

로

递

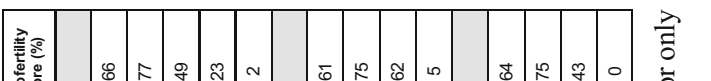

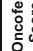

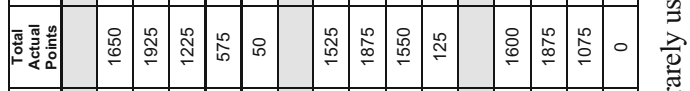

点

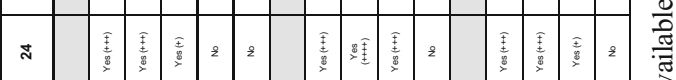

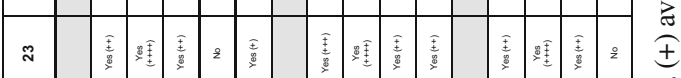

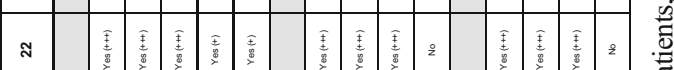

公

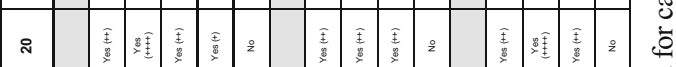

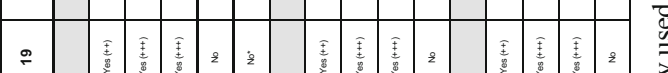

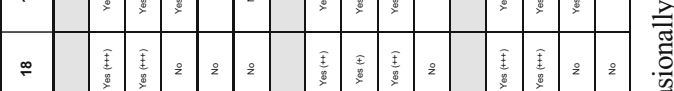

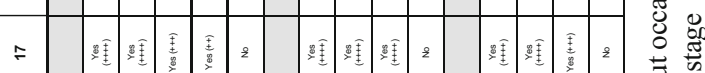

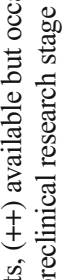

.0

氖:

혼

过

중

흘

워

충

음

$=$

$=$

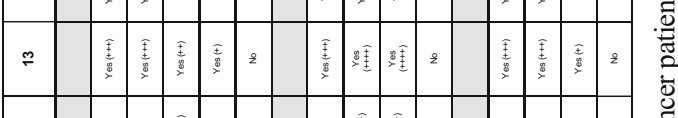

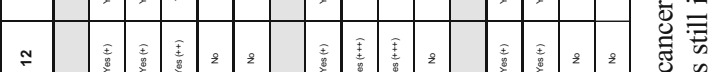

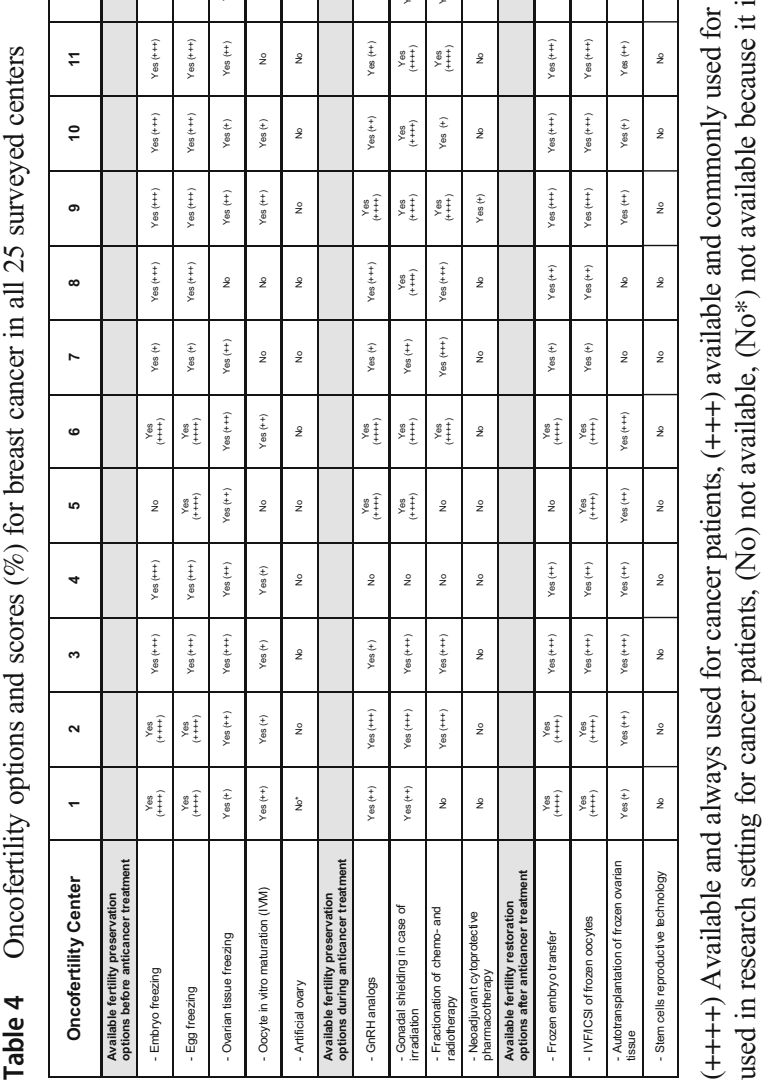




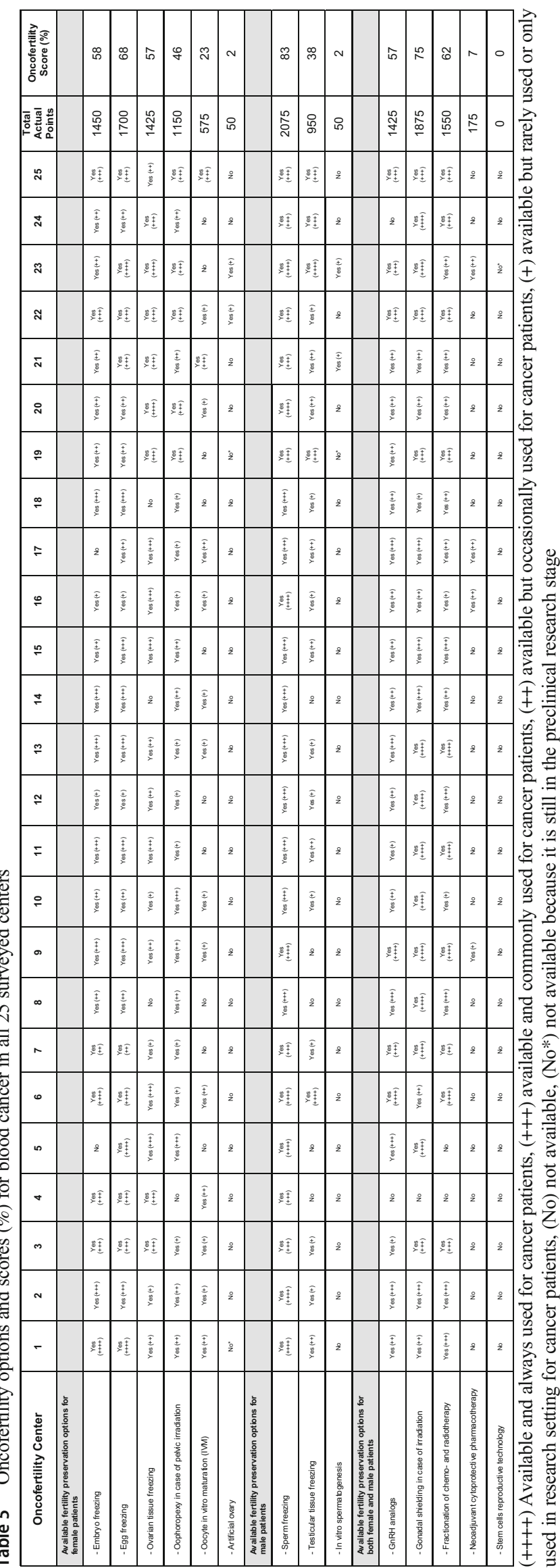

expectations around relationships, pregnancy, and parenthood [43]. When the patient becomes an adult and wishes to have children, fertility restoration may be possible using stored gonadal tissue or gametes. Autotransplantation of gonadal tissue can be offered to restore fertility but it should be handled with caution in patients with leukemia due to possible contamination of gonadal tissue with leukemic cells. According to few reports, harvesting gonadal tissue after the first cycles of anticancer therapy and during complete remission followed by proper gonadal tissue assessment for minimal residual disease (MRD) may reduce the risk of reintroducing leukemic cells with autotransplantation $[44,45]$. For additional safety measures, it may be a possible option for patients with leukemia to remove the transplanted gonadal tissue later after restoring fertility and having biological children $[46,47]$. Stem cell reproductive technology may be promising in research settings but it is not yet clinically proven as an effective oncofertility option (Table 6).

\section{Installing oncofertility programs for breast cancer in optimum resource settings}

Breast cancer is the most common cancer in women during their reproductive years. Breast cancer may require aggressive gonadotoxic anticancer therapy and hence necessitate prior fertility preservation measures. Women with $B R C A 1$ or $B R C A 2$ mutations carry significantly higher risks to develop breast and ovarian cancers (hereditary breast-ovarian cancer syndrome; HBOC), and they should receive appropriate oncofertility care as well. According to a recent large study, the cumulative breast cancer risk is $72 \%$ for $B R C A 1$ and $69 \%$ for $B R C A 2$ carriers, while the cumulative ovarian cancer risk is $44 \%$ for $B R C A 1$ and $17 \%$ for $B R C A 2$ carriers [48]. Unique medical challenges in oncofertility programs for breast cancer exist and include the following: (1) conventional ovarian stimulation prior to egg or embryo freezing results in elevated serum estradiol levels that should be avoided in estrogen sensitive malignancies such as breast cancer, and (2) autotransplantation of frozen ovarian tissue in patients with $B R C A$ mutations should be handled with caution due to significantly higher risks of developing ovarian cancer [49-53].

According to the aforementioned unique medical challenges as well as the responses and their calculated oncofertility scores (Table 4 and Fig. 4), we suggest installing the following oncofertility programs for breast cancer in optimum resource settings. Before initiation of anticancer therapy, freezing of eggs or embryos should be attempted with a random-start protocol for controlled ovarian stimulation and using letrozole or tamoxifen to avoid high estradiol levels. Freezing of ovarian tissue should be attempted when possible. In vitro maturation and further vitrification of oocytes retrieved in vivo or ex vivo from the extracted ovarian tissue (ovarian tissue oocytes in vitro maturation; OTO-IVM) could be attempted [54-56]. Artificial ovary technology is still experimental and cannot be relied upon alone as an 


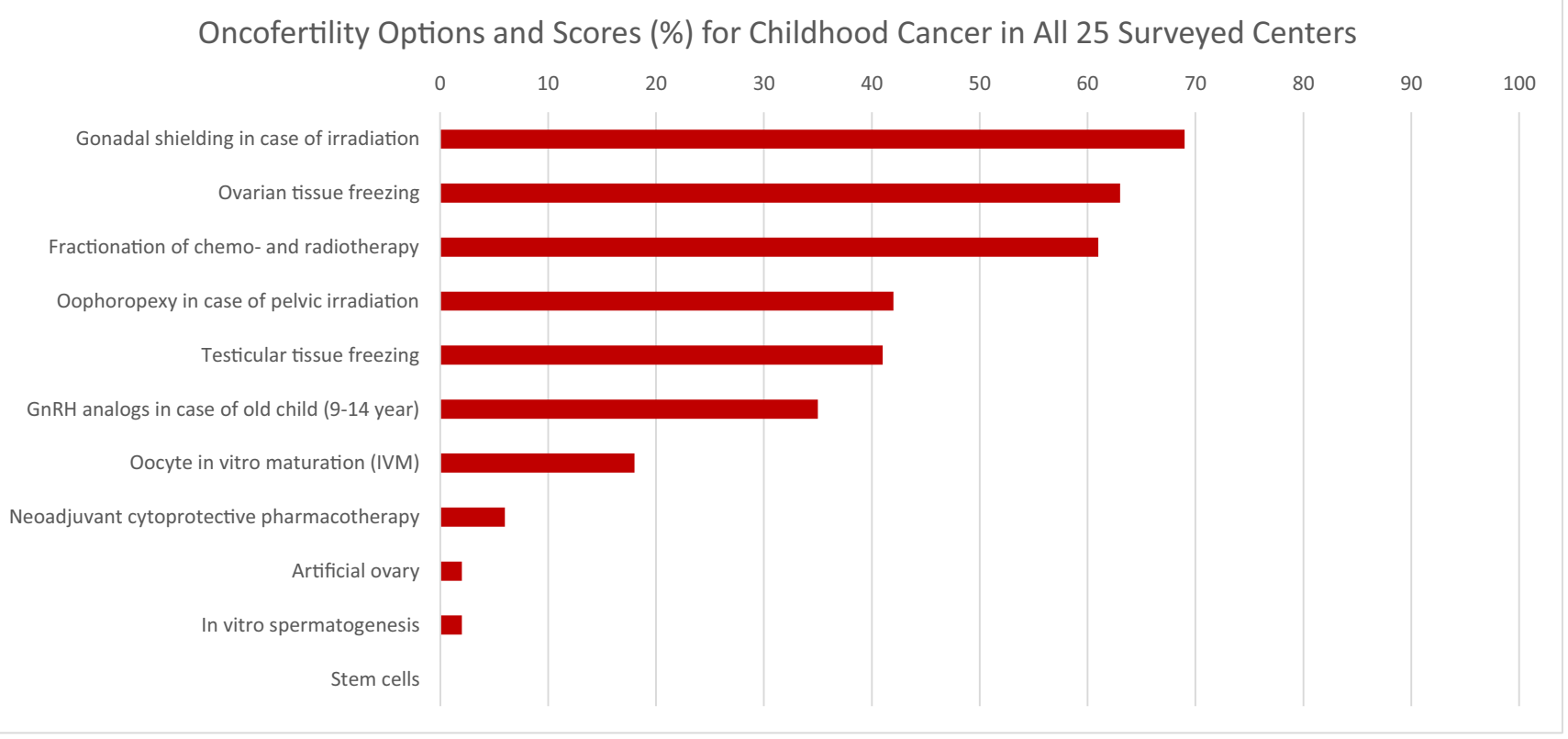

Fig. 3 Oncofertility options and scores (\%) for childhood cancer in all 25 surveyed centers

effective oncofertility option. Although experimental, oocyte IVM and artificial ovary technology aim to provide safe alternatives to avoid future ovarian tissue autotransplantation and potential reintroduction of malignant cells. During anticancer therapy, GnRH analog administration before and during chemotherapy can be considered. Fractionation of chemo- and radiotherapy could be attempted whenever deemed feasible by the oncologists. Gonadal shielding might be needed in case of combined irradiation to ovaries. Neoadjuvant cytoprotective pharmacotherapy is still experimental and not yet clinically proven as an effective oncofertility option. After anticancer therapy, fertility restoration may be achieved by frozen embryo transfer, or in vitro fertilization of stored oocytes. Patients with $B R C A$ mutations could be advised to use preimplantation genetic testing (PGT) during in vitro fertilization to avoid transmitting the mutation. Autotransplantation of frozen ovarian tissue can be offered to restore fertility but it should be handled with caution in patients with $B R C A$ mutations due to significantly higher risks of developing ovarian cancer. Proper ovarian tissue assessment in patients with $B R C A$ mutations is mandatory to reduce the risk of reintroducing malignant cells with autotransplantation. For additional safety measures, it may be a possible option for patients with $B R C A$ mutations to remove the transplanted ovarian tissue as well as the remaining ovary (if any) after childbearing is complete and at the time of an elective caesarian section. Stem cell reproductive technology may be promising in research settings but it is not yet clinically proven as an effective oncofertility option (Table 6).

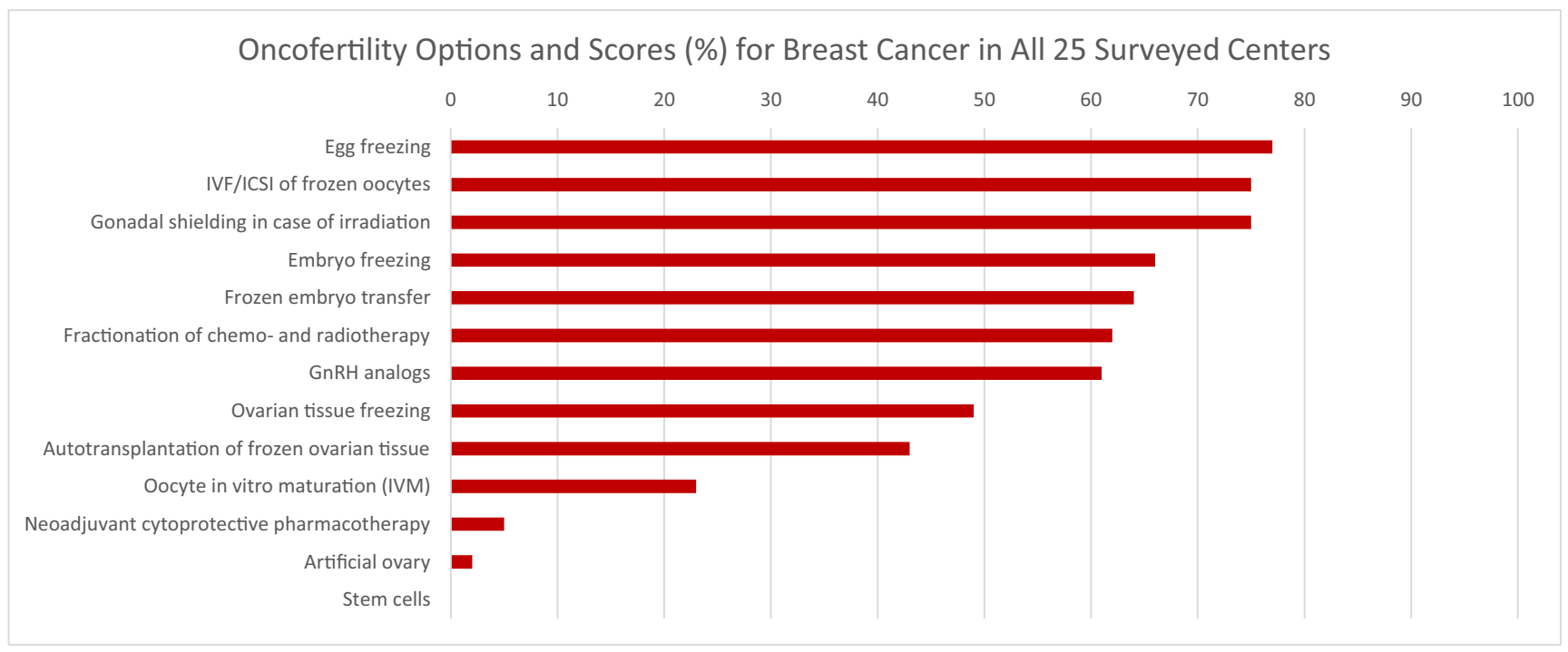

Fig. 4 Oncofertility options and scores (\%) for breast cancer in all 25 surveyed centers 


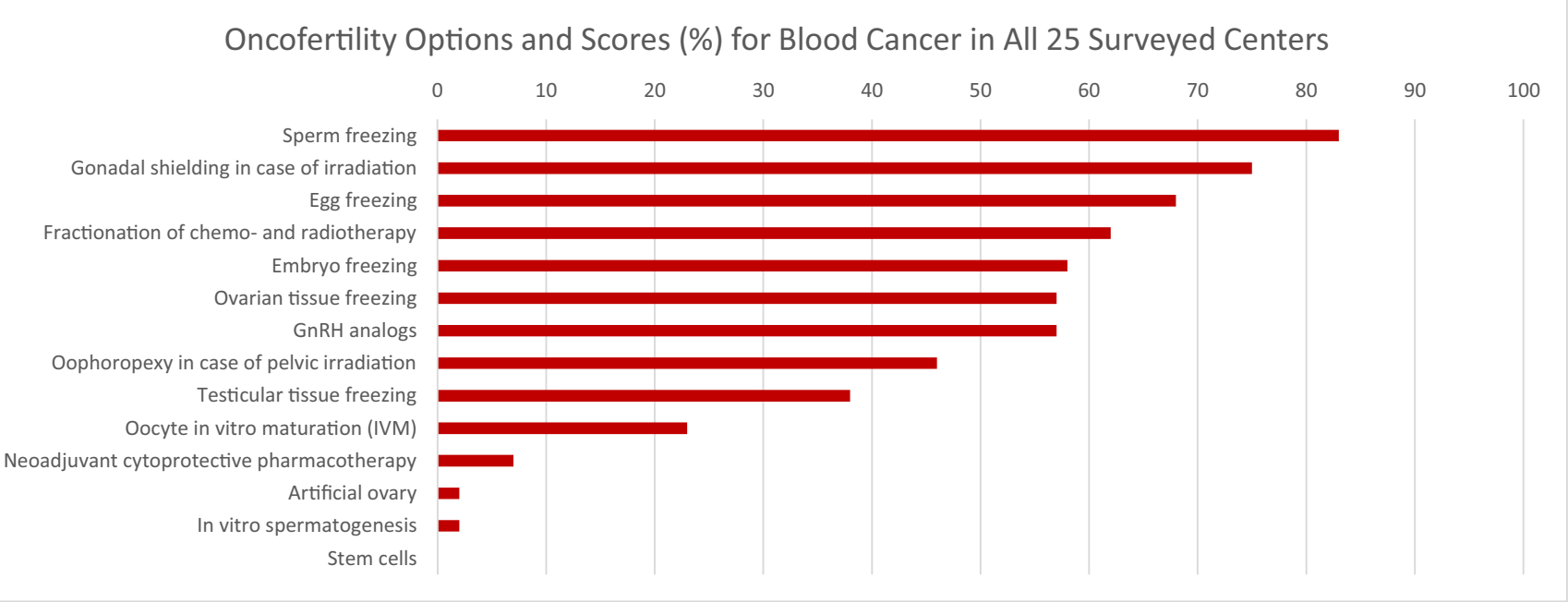

Fig. 5 Oncofertility options and scores (\%) for blood cancer in all 25 surveyed centers

\section{Installing oncofertility programs for blood cancer in optimum resource settings}

The common forms of blood cancers that occur during the reproductive age and may require immediate aggressive gonadotoxic anticancer therapy and hence necessitate prior fertility preservation measures are acute lymphocytic leukemia (ALL), acute myeloid leukemia (AML), non-Hodgkin lymphoma (NHL), and Hodgkin lymphoma (HL). Unique medical challenges in oncofertility programs for blood cancer exist and include the following: (1) most cases of blood cancer especially leukemia necessitate immediate initiation of anticancer therapy leaving very short time to offer fertility preservation options, thus may be precluded by the health status of the patient and the time available, and (2) autotransplantation of frozen gonadal tissue may carry the risk of reintroducing malignant cells, especially in leukemia [57-59].

According to the aforementioned unique medical challenges as well as the responses and their calculated oncofertility scores (Table 5 and Fig. 5), we suggest installing the following oncofertility programs for blood cancer in optimum resource settings. Before initiation of anticancer therapy, freezing of embryos or gametes (oocytes or spermatozoa) should be attempted when possible. Freezing of gonadal tissues (ovarian or testicular tissue) should be attempted after proper tissue assessment to exclude contamination with malignant cells. In vitro maturation and further vitrification of gametes retrieved in vivo or ex vivo from the extracted gonadal tissue could be attempted. Artificial gonad technology is still experimental and cannot be relied upon alone as an effective oncofertility option. Although experimental, these emerging technologies of in vitro maturation of gametes and artificial gonads aim to provide safe alternatives to avoid future gonadal tissue autotransplantation and potential reintroduction of malignant cells. Oophoropexy before female pelvis irradiation should be attempted when possible. During anticancer therapy, gonadal shielding in case of irradiation should be attempted. Fractionation of chemo- and radiotherapy could be attempted whenever deemed feasible by the oncologists. Use of GnRH analogs to preserve fertility during chemotherapy in case of hematological malignancies is widely debated and needs more research to inform evidence-based practice. Neoadjuvant cytoprotective pharmacotherapy is still experimental and not yet clinically proven as an effective oncofertility option. After anticancer therapy, fertility restoration may be achieved by frozen embryo transfer, or in vitro fertilization of stored gametes. Autotransplantation of frozen gonadal tissue can be offered to restore fertility but it should be handled with caution in patients with leukemia due to possible contamination of gonadal tissue with leukemic cells. According to a few reports, harvesting gonadal tissue after the first cycles of anticancer therapy and during complete remission followed by proper gonadal tissue assessment for minimal residual disease (MRD) may reduce the risk of reintroducing leukemic cells with autotransplantation. For additional safety measures, it may be a possible option for patients with leukemia to remove the transplanted gonadal tissue later after restoring fertility and having biological children [46, 47]. Stem cell reproductive technology may be promising in research settings but it is not yet clinically proven as an effective oncofertility option (Table 6).

After installation of these specific oncofertility programs for common cancers in optimum resource settings, we encourage using the "oncofertility score" as a prognostic tool to follow up on the development of these new oncofertility programs over time.

In cases where oncofertility options are rejected, contraindicated, infeasible, unsuccessful, or unavailable, adoption and 


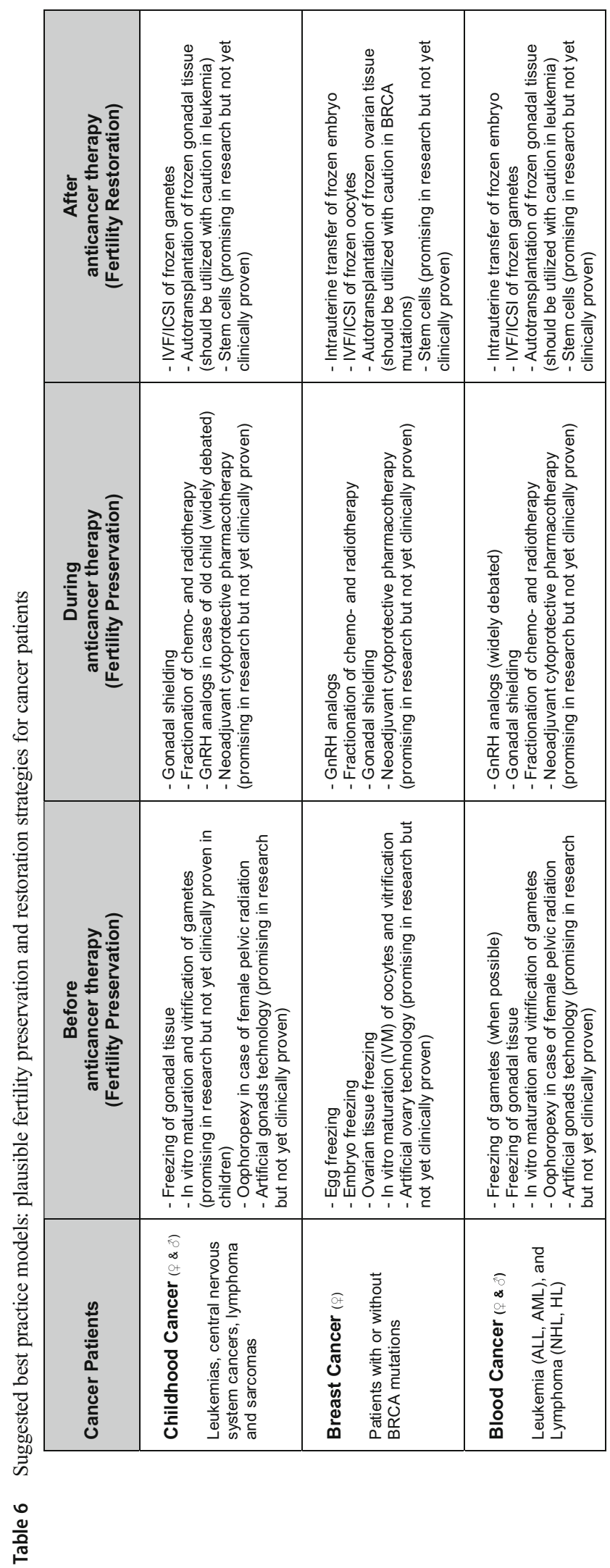

third-party reproduction, such as sperm, egg, and embryo donation and surrogacy, can be offered as family building alternatives.

\section{Next steps and future directions of Repro-Can-OPEN Studies}

In our next Repro-Can-OPEN studies, we are planning to investigate in detail the oncofertility programs offered to leukemia and lymphoma patients according to their gender and age group. We are planning also to investigate other cancers as well as other patient groups (e.g., LGBTQ population: lesbian, gay, bisexual, transgender, and queer or questioning) who were not included in our previous studies. We will provide further discussions on the advanced and the emerging oncofertility options, and highlight the recent achievements in the related preclinical research [60-65]. The Oncofertility Consortium will continue to engage more stakeholders from the USA and abroad to help build a sustainable oncofertility core competency worldwide.

\section{Conclusion}

Our Repro-Can-OPEN Study Part 2 proposed installing specific oncofertility programs for common cancers in optimum resource settings as an extrapolation for best practice models. Responses for childhood, breast, and blood cancers and their calculated oncofertility scores showed three major characteristics of oncofertility practice in optimum resource settings: (1) strong utilization of sperm freezing, egg freezing, embryo freezing, ovarian tissue freezing, gonadal shielding, and fractionation of chemo- and radiotherapy; (2) promising utilization of $\mathrm{GnRH}$ analogs, oophoropexy, testicular tissue freezing, and oocyte in vitro maturation (IVM); and (3) rare utilization of neoadjuvant cytoprotective pharmacotherapy, artificial ovary, in vitro spermatogenesis, and stem cell reproductive technology as they are still in preclinical or early clinical research settings. Proper technical and ethical concerns should be considered when offering advanced and experimental oncofertility options to patients. Dissemination of our study results and recommendations will provide efficient oncofertility edification and modeling to oncofertility teams and related healthcare providers around the globe and help them offer the best care possible to their patients.

Acknowledgments Collaborators of Practice Committee of the Oncofertility Consortium

Mahmoud Salama (Oncofertility Consortium, Feinberg School of Medicine, Northwestern University, Chicago, IL 60611, USA; mahmoud.salama@northwestern.edu, eaims_gm@yahoo.com),

Monica M. Laronda (Ann \& Robert H. Lurie Children's Hospital of Chicago, 225 East Chicago Ave, Box 63, Chicago IL, 60611, USA; mlaronda@northwestern.edu) 
Erin Rowell (Ann \& Robert H. Lurie Children's Hospital of Chicago, 225 East Chicago Ave, Box 63, Chicago IL, 60611, USA; erowell@luriechildrens.org)

Laura Erickson (Ann \& Robert H. Lurie Children's Hospital of Chicago, 225 East Chicago Ave, Box 63, Chicago IL, 60611, USA; lerickson@luriechildrens.org)

Kara Goldman (Oncofertility Consortium, Feinberg School of Medicine, Northwestern University, Chicago, IL 60611, USA; kara.goldman@nm.org)

Kristin Smith (Oncofertility Consortium, Feinberg School of Medicine, Northwestern University, Chicago, IL 60611, USA; ksmith@nm.org)

MaryEllen Pavone (Oncofertility Consortium, Feinberg School of Medicine, Northwestern University, Chicago, IL 60611, USA; MaryEllen.Pavone@nm.org)

Francesca E. Duncan (Oncofertility Consortium, Feinberg School of Medicine, Northwestern University, Chicago, IL 60611, USA; fduncan@ northwestern.edu)

Robert Brannigan (Oncofertility Consortium, Feinberg School of Medicine, Northwestern University, Chicago, IL 60611, USA; robert.brannigan@nm.org)

Lauren Ataman-Millhouse (Oncofertility Consortium, Feinberg School of Medicine, Northwestern University, Chicago, IL 60611, USA; lauren.ataman@northwestern.edu)

Pasquale Patrizio (Yale Fertility Center and Yale Fertility Preservation program, 200 West Campus Dr., Orange, CT 06477, USA; pasquale.patrizio@yale.edu)

Kenny A. Rodriguez-Wallberg (Karolinska Institutet, Department of Oncology-Pathology and Karolinska University Hospital, Department of Reproductive Medicine, Division of Gynecology and Reproduction, SE14186, Stockholm, Sweden; kenny.rodriguez-wallberg@ki.se)

Yuki Okutsu-Horage (Department of Obstetrics and Gynecology, St. Marianna University School of Medicine, 2-16-1, Sugao, Miyamae-ku, Kawasaki, Kanagawa, Japan; y2okutsu@marianna-u.ac.jp)

Nao Suzuki (Department of Obstetrics and Gynecology, St. Marianna University School of Medicine, 2-16-1, Sugao, Miyamae-ku, Kawasaki, Kanagawa, Japan; nao@marianna-u.ac.jp)

Matteo Lambertini (Department of Medical Oncology, UOC Clinica di Oncologia Medica, IRCCS Ospedale Policlinico San Martino, Genova, Italy; Department of Internal Medicine and Medical Specialties (DiMI), School of Medicine, University of Genova, Genova, Italy; matteo.lambertini@unige.it)

Catharyn (Kate) Stern (Fertility Preservation Service, Reproductive Services Unit, Royal Women's Hospital, Parkville, 3051, Australia; Fertility Preservation Service, Melbourne IVF, East Melbourne, 3002, Australia; Kate.stern@mivf.com.au)

Veronica Gomez-Lobo (Children's National Hospital, 111 Michigan Avenue NW, Washington, DC 20010, USA. (ZIA\# HD008985); Veronica.gomez-lobo@nih.gov)

Jacqueline Y. Maher (Children's National Hospital, 111 Michigan Avenue NW, Washington, DC 20010, USA. (ZIA\# HD008985); Jacqueline.maher@nih.gov)

Michael H. Hsieh (Children's National Hospital, 111 Michigan Avenue NW, Washington, DC 20010, USA. (ZIA\# HD008985); mhsieh@childrensnational.org)

Molly B. Moravek (Center for Reproductive Medicine, Michigan Medicine, 475 Market Place, Building 1, Suite B, Ann Arbor, MI 48108, USA; mpenderg@med.umich.edu)

Antoinette Anazodo (Fertility Research Centre, Royal Hospital for Women, Barker Street, Sydney, Australia; Antoinette.anazodo@health.nsw.gov.au)

Lynn M. Westphal (Stanford University Medical Center, 300 Pasteur Drive, Stanford, CA, USA; lynnw@stanford.edu)

Richard A. Anderson (University of Edinburgh, Edinburgh, UK; Royal Infirmary of Edinburgh and Royal Hospital for Children and Young People, Little France Crescent, Edinburgh, UK; Richard.anderson@ed.ac.uk)
W. Hamish Wallace (University of Edinburgh, Edinburgh, UK; Royal Infirmary of Edinburgh and Royal Hospital for Children and Young People, Little France Crescent, Edinburgh, UK; hamish.wallace@nhs.net)

Rod T. Mitchell (University of Edinburgh, Edinburgh, UK; Royal Infirmary of Edinburgh and Royal Hospital for Children and Young People, Little France Crescent, Edinburgh, UK; Rod.Mitchell@ed.ac.uk) Leena Nahata (Nationwide Children's Hospital, 700 Children's Dr., Columbus, OH 43205, USA; Leena.nahata@nationwidechildrens.org)

Stacy Whiteside (Nationwide Children's Hospital, 700 Children's Dr., Columbus, OH 43205, USA; Stacy.whiteside@ nationwidechildrens.org) Suneeta Senapati (University of Pennsylvania, Division of Reproductive Endocrinology \& Infertility, 3701 Market Street, Suite 8000, Philadelphia, PA 19104, USA; suneeta.senapati@pennmedicine.upenn.edu)

Divya K. Shah (University of Pennsylvania, Division of Reproductive Endocrinology \& Infertility, 3701 Market Street, Suite 8000, Philadelphia, PA 19104, USA; divya.shah@pennmedicine.upenn.edu)

Clarisa Gracia (University of Pennsylvania, Division of Reproductive Endocrinology \& Infertility, 3701 Market Street, Suite 8000, Philadelphia, PA 19104, USA; clarisa.gracia@ pennmedicine.upenn.edu)

M. Elizabeth Fino (New York University, NYU Langone Fertility Center, 660 First Ave, 5th Floor, New York, NY 10016, USA; Mary.Fino@nyulangone.org)

Jennifer K. Blakemore (New York University, NYU Langone Fertility Center, 660 First Ave, 5th Floor, New York, NY 10016, USA; Jennifer.Blakemore@nyulangone.org)

Gwendolyn P. Quinn (New York University, NYU Langone Fertility Center, 660 First Ave, 5th Floor, New York, NY 10016, USA; Gwendolyn.Quinn@nyulangone.org)

Jan-Steffen Krüssel (UniKiD - Center for Reproductive Medicine, UniCareD - Center for Fertility Preservation, Düsseldorf University Hospital, Moorenstrasse 5, D-40225 Düsseldorf, Germany; kruessel@unikid.de)

Dunja-Maria Baston-Büst (UniKiD - Center for Reproductive Medicine, UniCareD - Center for Fertility Preservation, Düsseldorf University Hospital, Moorenstrasse 5, D-40225 Düsseldorf, Germany; baston-buest@unikid.de)

Jana Liebenthron (UniKiD - Center for Reproductive Medicine, UniCareD - Center for Fertility Preservation, Düsseldorf University Hospital, Moorenstrasse 5, D-40225 Düsseldorf, Germany; jana.liebenthron@unicared.de)

Claus Yding Andersen (Laboratory of Reproductive Biology, Juliane Marie Centre for Women, Children and Reproduction, University Hospital of Copenhagen, Blegdamsvej 9, DK-2100 Copenhagen, Denmark; yding@ rh.dk)

Stine Gry Kristensen (Laboratory of Reproductive Biology, Juliane Marie Centre for Women, Children and Reproduction, University Hospital of Copenhagen, Blegdamsvej 9, DK-2100 Copenhagen, Denmark; Stine.Gry.Kristensen@regionh.dk)

Linn Salto Mamsen (Laboratory of Reproductive Biology, Juliane Marie Centre for Women, Children and Reproduction, University Hospital of Copenhagen, Blegdamsvej 9, DK-2100 Copenhagen, Denmark; linn.salto.mamsen@regionh.dk)

Yasmin Jayasinghe (Fertility Preservation Service, The Royal Children's Hospital, Flemington Rd, Parkville, Melbourne, Vic 3054, Australia; Yasmin.jayasinghe@unimelb.edu.au)

H. Irene Su (University of California, San Diego, 3855 Health Sciences Drive, La Jolla, CA 92039-0901, USA; hisu@health.ucsd.edu) Marie-Madeleine Dolmans (Cliniques Universitaires Saint Luc, Université Catholique de Louvain, Avenue Hippocrate, 10, 1200 Brussels, Belgium; marie-madeleine.dolmans@uclouvain.be)

Christiani A. Amorim (Université Catholique de Louvain, Avenue Mounier 52, 1200 Brussels, Belgium; christiani.amorim@uclouvain.be)

Isabelle Demeestere (Fertility Clinic and Research Laboratory on Human Reproduction, CUB-Erasme Hospital, Université Libre de Bruxelles (ULB), 808 route de Lennik, 1070 Brussels, Belgium; idemeest@ulb.ac.be) 
Michel De Vos (Centre for Reproductive Medicine of UZ Brussel, Laarbeeklaan 101, 1090 Brussels, Belgium; Michel.devos@uzbrussel.be)

Ellen Van Moer (Centre for Reproductive Medicine of UZ Brussel, Laarbeeklaan 101, 1090 Brussels, Belgium; Ellen.vanmoer@uzbrussel.be)

Vladimir Isachenko (Gynecological Endocrinology and Reproductive Medicine Division, Obstetrics and Gynecology Department, Cologne University Hospital, Cologne, Germany; vladimir.isachenko@ukkoeln.de)

Evgenia Isachenko (Gynecological Endocrinology and Reproductive Medicine Division, Obstetrics and Gynecology Department, Cologne University Hospital, Cologne, Germany; evgenia.isachenko@ukkoeln.de)

Peter Mallmann (Gynecological Endocrinology and Reproductive Medicine Division, Obstetrics and Gynecology Department, Cologne University Hospital, Cologne, Germany; peter.mallmann@uk-koeln.de)

Gohar Rahimi (Gynecological Endocrinology and Reproductive Medicine Division, Obstetrics and Gynecology Department, Cologne University Hospital, Cologne, Germany; gohar.rahimi@uk-koeln.de)

Hanna Valli-Pulaski (Center for Reproduction and Transplantation, Magee-Womens Hospital, University of Pittsburgh Medical Center, 300 Halket Street, Pittsburgh, PA 15213, USA; vallih2@mwri.magee.edu)

Sarah R. Steimer (Center for Reproduction and Transplantation, MageeWomens Hospital, University of Pittsburgh Medical Center, 300 Halket Street, Pittsburgh, PA 15213, USA; steimersr2@mwri.magee.edu)

Katherine V. McMahon (Center for Reproduction and Transplantation, Magee-Womens Hospital, University of Pittsburgh Medical Center, 300 Halket Street, Pittsburgh, PA 15213, USA; samskv@upmc.edu)

Kyle E. Orwig (Center for Reproduction and Transplantation, MageeWomens Hospital, University of Pittsburgh Medical Center, 300 Halket Street, Pittsburgh, PA 15213, USA; orwigke@upmc.edu)

Julie Sroga Rios (University of Cincinnati, Department of Obstetrics and Gynecology, Division for REI, Cincinnati, OH 45229, USA; Cincinnati Children's Hospital Medical Center, Division of Pediatric Adolescent Gynecology Pediatric, Cincinnati, OH 45229, USA; Julie.rios@cchmc.org)

James F. Smith (Urology Department, UCSF Medical Center, University of California, San Francisco, CA 94143, USA; James.smith@ucsf.edu)

Evelyn Mok-Lin (Obstetrics and Gynecology Department, UCSF Medical Center, University of California, San Francisco, CA 94143, USA; Evelyn.Mok-Lin@ucsf.edu)

Teresa K. Woodruff (Oncofertility Consortium, Feinberg School of Medicine, Northwestern University, Chicago, IL 60611, USA; tkw@northwestern.edu,TeresaWoodruff1989@alum.northwestern.edu).

Funding This study received support from Northwestern University institutional funds from The Thomas J. Watkins Professor of Obstetrics and Gynecology.

\section{Compliance with ethical standards}

Conflict of interest Matteo Lambertini acted as a consultant for Roche and Novartis, and received honoraria from Theramex, Roche, Novartis, Takeda, Pfizer, and Lilly outside the submitted work. Yasmin Jayasinghe has received educational funds from Merck outside the submitted work. The other collaborators have declared no conflicts of interest.

\section{References}

1. Oktay K, Harvey BE, Partridge AH, Quinn GP, Reinecke J, Taylor HS, et al. Fertility preservation in patients with cancer: ASCO clinical practice guideline update. J Clin Oncol. 2018;36(19): 1994-2001.

2. Practice Committee of the American Society for Reproductive Medicine (ASRM). Fertility preservation in patients undergoing gonadotoxic therapy or gonadectomy: a committee opinion. Fertil Steril. 2019;112(6):1022-33.

3. Oncofertility Consortium - Northwestern University [Internet]. [cited 2020 Aug 1]. Available from: <http://oncofertility.northwestern. edu/>.

4. Oncofertility Professional Engagement Network (OPEN) Northwestern University [Internet]. [cited 2020 Aug 1]. Available from: <http://oncofertility.northwestern.edu/oncofertilityprofessional-engagement-network $>$.

5. Ataman LM, Rodrigues JK, Marinho RM, Caetano JP, Chehin MB, Alves da Motta EL, et al. Creating a global community of practice for oncofertility. J Glob Oncol. 2016;2(2):83-96.

6. Rashedi A, de Roo SF, Ataman L, et al. A survey of fertility preservation options available to cancer patients around the globe. J Glob Oncol. 2018:4:1-16.

7. Rashedi A, de Roo SF, Ataman L, Edmonds ME, Silva AA, Scarella A, et al. A survey of third-party parenting options associated with fertility preservation available to patients with cancer around the globe. J Glob Oncol. 2018;4:1-7.

8. Salama M, Ataman L, Taha T, et al. Building oncofertility core competency in developing countries: experience from Egypt, Tunisia, Brazil, Peru, and Panama. J Glob Oncol. 2018;4:1-11.

9. Salama M, Ataman-Millhouse L, Sobral F, Terrado G, Scarella A, Bourlon MT, et al. Barriers and opportunities of oncofertility practice in nine developing countries and the emerging oncofertility professional engagement network. J Glob Oncol. 2018;4:1-7.

10. Salama M, Ataman-Millhouse L, Braham M, Berjeb K, Khrouf M, Rodrigues JK, et al. Installing oncofertility programs for common cancers in limited resource settings (Repro-Can-OPEN Study): an extrapolation during the global crisis of Coronavirus (COVID-19) pandemic. J Assist Reprod Genet. 2020;37(7):1567-77.

11. McDougall R, Gillam L, Delany C, Jayasinghe Y. The ethics of fertility preservation for prepubertal children: should clinicians offer procedures where efficacy is largely unproven? J Med Ethics. 2018;44(1):27-31.

12. Allan $\mathrm{S}$, Gook D, Jayasinghe Y. The impact of the law in helping or hindering fertility preservation for children with cancer facing gonadotoxic therapies. Journal of Law and Medicine. 2018;26(2): 322-33.

13. Anazodo A, Laws P, Logan S, Saunders C, Travaglia J, Gerstl B, et al. How can we improve oncofertility care for patients? A systematic scoping review of current international practice and models of care. Hum Reprod Update. 2019;25(2):159-79.

14. Anazodo A, Laws P, Logan S, Saunders C, Travaglia J, Gerstl B, et al. The development of an international oncofertility competency framework: a model to increase oncofertility implementation. Oncologist. 2019;24:e1450-9.

15. Salama M, Woodruff TK. Anticancer treatments and female fertility: clinical concerns and role of oncologists in oncofertility practice. Expert Rev Anticancer Ther. 2017;17(8):687-92.

16. Nahata L, Anazodo A, Cherven B, et al. Optimizing health literacy to facilitate reproductive health decision-making in adolescent and young adults with cancer [published online ahead of print, 2020 Jul 6]. Pediatr Blood Cancer. 2020;e28476.

17. Saraf AJ, Stanek J, Audino A, DaJusta D, Hansen-Moore J, McCracken K, et al. Examining predictors and outcomes of fertility consults among children, adolescents, and young adults with cancer. Pediatr Blood Cancer. 2018;65(12):e27409.

18. Demeestere I, Ferster A. Fertility preservation counselling for childhood cancer survivors. Lancet Oncol. 2020;21(3):329-30. https:// doi.org/10.1016/S1470-2045(20)30065-6. 
19. Peccatori FA, Azim HA Jr, Orecchia R, Hoekstra HJ, Pavlidis N, Kesic V, et al. Cancer, pregnancy and fertility: ESMO Clinical Practice Guidelines for diagnosis, treatment and follow-up. Ann Oncol. 2013;24 Suppl 6:vi160-70.

20. Loren AW, Mangu PB, Beck LN, Brennan L, Magdalinski AJ, Partridge $\mathrm{AH}$, et al. Fertility preservation for patients with cancer: American Society of Clinical Oncology clinical practice guideline update. J Clin Oncol. 2013;31(19):2500-10.

21. Practice Committee of American Society for Reproductive Medicine. Fertility preservation in patients undergoing gonadotoxic therapy or gonadectomy: a committee opinion. Fertil Steril. 2013;100(5):1214-23.

22. Ethics Committee of American Society for Reproductive Medicine. Fertility preservation and reproduction in patients facing gonadotoxic therapies: a committee opinion. Fertil Steril. 2013;100(5):1224-31.

23. Martinez F. Update on fertility preservation from the Barcelona International Society for Fertility Preservation-ESHRE-ASRM 2015 expert meeting: indications, results and future perspectives. Hum Reprod. 2017;32(9):1802-11.

24. Coccia PF, Pappo AS, Beaupin L, Borges VF, Borinstein SC, Chugh R, et al. Adolescent and young adult oncology, Version 2.2018, NCCN Clinical Practice Guidelines in Oncology. J Natl Compr Canc Netw. 2018;16(1):66-97.

25. Donnez J, Dolmans MM. Fertility preservation in women. N Engl J Med. 2017;377(17):1657-65.

26. Schüring AN, Fehm T, Behringer K, Goeckenjan M, Wimberger P, Henes M, et al. Practical recommendations for fertility preservation in women by the FertiPROTEKT network. Part I: Indications for fertility preservation. Arch Gynecol Obstet. 2018;297(1):241-55.

27. von Wolff M, Germeyer A, Liebenthron J, Korell M, Nawroth F. Practical recommendations for fertility preservation in women by the FertiPROTEKT network. Part II: fertility preservation techniques. Arch Gynecol Obstet. 2018;297(1):257-67.

28. von Wolff M, Andersen CY, Woodruff TK, Nawroth F. FertiPROTEKT, Oncofertility Consortium and the Danish Fertility-Preservation Networks-what can we learn from their experiences? Clin Med Insights Reprod Health. 2019;13: 1179558119845865.

29. Van der Ven H, Liebenthron J, Beckmann M, et al. Ninety-five orthotopic transplantations in 74 women of ovarian tissue after cytotoxic treatment in a fertility preservation network: tissue activity, pregnancy and delivery rates. Hum Reprod. 2016;31(9):2031-41.

30. Dittrich R, Kliesch S, Schüring A, Balcerek M, Baston-Büst DM, Beck $\mathrm{R}$, et al. Fertility preservation for patients with malignant disease. Guideline of the DGGG, DGU and DGRM (S2k-Level, AWMF Registry No. 015/082, November 2017) - Recommendations and Statements for Girls and Women. Geburtshilfe Frauenheilkd. 2018;78(6):567-84.

31. Lotz L, Dittrich R, Hoffmann I, Beckmann MW. Ovarian tissue transplantation: experience from Germany and worldwide efficacy. Clin Med Insights Reprod Health. 2019;13:1179558119867357.

32. Rodriguez-Wallberg KA, Tanbo T, Tinkanen H, Thurin-Kjellberg A, Nedstrand E, Kitlinski ML, et al. Ovarian tissue cryopreservation and transplantation among alternatives for fertility preservation in the Nordic countries-compilation of 20 years of multicenter experience. Acta Obstet Gynecol Scand. 2016;95(9):1015-26.

33. Rodriguez-Wallberg KA, Marklund A, Lundberg F, Wikander I, Milenkovic M, Anastacio A, et al. A prospective study of women and girls undergoing fertility preservation due to oncologic and non-oncologic indications in Sweden-Trends in patients' choices and benefit of the chosen methods after long-term follow up. Acta Obstet Gynecol Scand. 2019;98(5):604-15.

34. Rodriguez-Wallberg KA, Borgström B, Petersen C, ThurinKjellberg A, Mörse H, Giwercman A, et al. National guidelines and multilingual age-adapted patient brochures and videos as decision aids for fertility preservation (FP) of children and teenagers with cancer-a multidisciplinary effort to improve children's information and access to FP in Sweden. Acta Obstet Gynecol Scand. 2019;98(5):679-80.

35. Gellert SE, Pors SE, Kristensen SG, Bay-Bjørn AM, Ernst E, Yding AC. Transplantation of frozen-thawed ovarian tissue: an update on worldwide activity published in peer-reviewed papers and on the Danish cohort. J Assist Reprod Genet. 2018;35(4):561-70.

36. Salama M, Isachenko V, Isachenko E, Rahimi G, Mallmann P. Updates in preserving reproductive potential of prepubertal girls with cancer: systematic review. Crit Rev Oncol Hematol. 2016;103:10-21.

37. Nahata L, Woodruff TK, Quinn GP, Meacham LR, Chen D, Appiah LC, et al. Ovarian tissue cryopreservation as standard of care: what does this mean for pediatric populations? J Assist Reprod Genet. 2020;37(6):1323-6.

38. Salama M, Woodruff TK. New advances in ovarian autotransplantation to restore fertility in cancer patients. Cancer Metastasis Rev. 2015;34(4):807-22.

39. Corkum KS, Rhee DS, Wafford QE, Demeestere I, Dasgupta R, Baertschiger R, et al. Fertility and hormone preservation and restoration for female children and adolescents receiving gonadotoxic cancer treatments: a systematic review. J Pediatr Surg. 2019;54(11): $2200-9$.

40. Stukenborg JB, Wyns C. Fertility sparing strategies for pre- and peripubertal male cancer patients. Ecancermedicalscience. 2020;14:1016

41. Borgström B, Fridström M, Gustafsson B, Ljungman P, RodriguezWallberg KA. A prospective study on the long-term outcome of prepubertal and pubertal boys undergoing testicular biopsy for fertility preservation prior to hematologic stem cell transplantation. Pediatr Blood Cancer. 2020;67:e28507.

42. Ho WLC, Bourne H, Gook D, Clarke G, Kemertzis M, Stern K, et al. A short report on current fertility preservation strategies for boys. Clin Endocrinol (Oxf). 2017;87(3):279-85.

43. Jayasinghe $\mathrm{Y}$, Wallace $\mathrm{W}$, Anderson R. Ovarian function, fertility and reproductive lifespan in cancer patients. Expert Endocrinol Reviews. 2018;13(3):125-36.

44. Greve T, Clasen-Linde E, Andersen MT, Andersen MK, Sørensen $\mathrm{SD}$, Rosendahl M, et al. Cryopreserved ovarian cortex from patients with leukemia in complete remission contains no apparent viable malignant cells. Blood. 2012;120(22):4311-6.

45. Díaz-García C, Herraiz S, Such E, Andrés MDM, Villamón E, Mayordomo-Aranda E, et al. Dexamethasone does not prevent malignant cell reintroduction in leukemia patients undergoing ovarian transplant: risk assessment of leukemic cell transmission by a xenograft model. Hum Reprod. 2019;34(8):1485-93.

46. Shapira M, Raanani H, Barshack I, Amariglio N, Derech-Haim S, Marciano MN, et al. First delivery in a leukemia survivor after transplantation of cryopreserved ovarian tissue, evaluated for leukemia cells contamination. Fertil Steril. 2018;109(1):48-53.

47. Sonmezer M, Ozkavukcu S, Sukur YE, Kankaya D, Arslan O. First pregnancy and live birth in Turkey following frozen-thawed ovarian tissue transplantation in a patient with acute lymphoblastic leukemia who underwent cord blood transplantation. J Assist Reprod Genet. 2020. https://doi.org/10.1007/s10815-020-01850-2.

48. Kuchenbaecker KB, Hopper JL, Barnes DR, Phillips KA, Mooij $\mathrm{TM}$, Roos-Blom MJ, et al. Risks of breast, ovarian, and contralateral breast cancer for BRCA1 and BRCA2 mutation carriers. JAMA. 2017;317(23):2402-16.

49. Klemp JR, Kim SS, ISFP Practice Committee. Fertility preservation in young women with breast cancer. J Assist Reprod Genet. 2012;29(6):469-72.

50. Lambertini M, Goldrat O, Ferreira AR, Dechene J, Azim Jr HA, Desir J, et al. Reproductive potential and performance of fertility 
preservation strategies in BRCA-mutated breast cancer patients. Ann Oncol. 2018;29(1):237-43.

51. Lambertini M, Goldrat O, Toss A, Azim HA Jr, Peccatori FA, Ignatiadis $\mathrm{M}$, et al. Fertility and pregnancy issues in BRCAmutated breast cancer patients. Cancer Treat Rev. 2017;59:61-70.

52. Rodriguez-Wallberg KA, Oktay K. Fertility preservation and pregnancy in women with and without BRCA mutation-positive breast cancer. Oncologist. 2012;17(11):1409-17.

53. Lambertini M, Di Maio M, Poggio F, et al. Knowledge, attitudes and practice of physicians towards fertility and pregnancy-related issues in young BRCA-mutated breast cancer patients. Reprod Biomed Online. 2019;38(5):835-44.

54. Kedem A, Yerushalmi GM, Brengauz M, Raanani H, Orvieto R, Hourvitz A, et al. Outcome of immature oocytes collection of 119 cancer patients during ovarian tissue harvesting for fertility preservation. J Assist Reprod Genet. 2018;35(5):851-6.

55. Fasano $\mathrm{G}$, Dechène $\mathrm{J}$, Antonacci $\mathrm{R}$, Biramane $\mathrm{J}$, Vannin $\mathrm{AS}$, van Langendonckt A, et al. Outcomes of immature oocytes collected from ovarian tissue for cryopreservation in adult and prepubertal patients. Reprod Biomed Online. 2017;34(6):575-82.

56. Pereira N, Hubschmann AG, Lekovich JP, Schattman GL, Rosenwaks Z. Ex vivo retrieval and cryopreservation of oocytes from oophorectomized specimens for fertility preservation in a BRCA1 mutation carrier with ovarian cancer. Fertil Steril. 2017;108(2):357-60.

57. Donnez J, Dolmans MM. Preservation of fertility in females with haematological malignancy. Br J Haematol. 2011;154(2):175-84.

58. Jadoul P, Kim SS, ISFP Practice Committee. Fertility considerations in young women with hematological malignancies. J Assist Reprod Genet. 2012;29(6):479-87.
59. Salama M, Anazodo A, Woodruff TK. Preserving fertility in female patients with hematological malignancies: a multidisciplinary oncofertility approach. Ann Oncol. 2019;30(11):1760-75.

60. Laronda MM, Rutz AL, Xiao S, Whelan KA, Duncan FE, Roth $\mathrm{EW}$, et al. A bioprosthetic ovary created using $3 \mathrm{D}$ printed microporous scaffolds restores ovarian function in sterilized mice. Nat Commun. 2017;8:15261.

61. Xiao S, Coppeta JR, Rogers HB, Isenberg BC, Zhu J, Olalekan SA, et al. A microfluidic culture model of the human reproductive tract and 28-day menstrual cycle. Nat Commun. 2017;8:14584.

62. Jakus AE, Laronda MM, Rashedi AS, Robinson CM, Lee C, Jordan SW, et al. "Tissue papers" from organ-specific decellularized extracellular matrices. Adv Funct Mater. 2017;27(3):1700992.

63. Salama M, Woodruff TK. From bench to bedside: current developments and future possibilities of artificial human ovary to restore fertility. Acta Obstet Gynecol Scand. 2019;98(5):659-64.

64. Hermann BP, Sukhwani M, Winkler F, Pascarella JN, Peters KA, Sheng Y, et al. Spermatogonial stem cell transplantation into rhesus testes regenerates spermatogenesis producing functional sperm. Cell Stem Cell. 2012;11(5):715-26.

65. Fayomi AP, Peters K, Sukhwani M, Valli-Pulaski H, Shetty G, Meistrich ML, et al. Autologous grafting of cryopreserved prepubertal rhesus testis produces sperm and offspring. Science. 2019;363(6433):1314-9.

Publisher's note Springer Nature remains neutral with regard to jurisdictional claims in published maps and institutional affiliations. 